\title{
Skills or culture? An analysis of the decision to work by immigrant women in Italy
}

\author{
Antonio Accetturo ${ }^{1 *}$ and Luigi Infante ${ }^{2}$
}

\author{
* Correspondence: antonio. \\ accetturo@bancaditalia.it \\ ${ }^{1}$ Structural Economic Analysis \\ Department - Bank of Italy, Rome, \\ Italy \\ Full list of author information is \\ available at the end of the article
}

\begin{abstract}
Activity and employment rates for immigrant women in many industrialised countries display a great variability across national groups. The aim of this paper is to assess whether this fact is due to a voluntary decision (i.e. large reservation wages by immigrants) or to an involuntary process (i.e. low labor market evaluation of their skills). This is done by estimating the reservation wage for each individual in a sample of immigrant women in Italy. Our results show that low activity and employment rates for certain national groups are not associated with high reservation wages. This implies that low participation should not be interpreted as a voluntary decision.
\end{abstract}

JEL codes: J22, J61, J15

Keywords: Reservation wages, Female labor supply, Cross-national differences

\section{Introduction}

The immigrant labor force makes an essential contribution to the growth and development of most of the industrialised countries. At the beginning of the 2000s, 85 million people residing in the OECD countries had been born abroad, almost three times more than in the 1960s. The share of immigrants over total population is quite high for economically advanced countries and it ranges from 6 per cent in Italy to almost 25 per cent in Canada.

In many European countries, characterised by a rapidly aging population, the economic integration of immigrants is a necessary condition for the achievement of the Lisbon targets of full employment and sustainable growth under the European Employment Strategy. However, although labor market integration for immigrant men is not generally an issue, employment rates for women are often low and characterised by great variability according to country of origin.

There are two possible explanations for this fact. The first is based on "cultural bias". For certain nationalities, gender differences in the division of the family burden may play an important role in the labor supply. In other words, traditions may relegate women to the more traditional roles and tasks of housekeeping and child-raising. The second is a skill mismatch on the labor market. In this case, immigrants are willing to work outside the family but their human capital does not satisfy local employers' requirements.

The aim of this paper is to disentangle these two effects by assessing the impact of cultural background on women's decision to participate in the labor market. In 
particular, we investigate whether the observed high variability in the employment and activity rates across nationalities is attributable to a cultural or a skill effect by estimating individual reservation wages.

We make use of an extremely rich database compiled by the non-governmental organization Iniziative e Studi sulla Multietnicità - ISMU (Initiatives and Studies on Multiethnic Society) from surveys of immigrants from the least developed, emerging and transition countries now resident in the region of Lombardy in the North-West of Italy. The fact that the interviews are collected in the same (relatively small) area of Italy is particularly useful for our analysis. Interviewees should face the same labor market conditions; moreover, given Italy's recent tradition in immigration, they are most likely to preserve their cultural attitudes with respect to labor market participation.

The integration of immigrant women in the labor market is particularly important for policy making. If the cultural bias explanation were true, the best response for a policy maker willing to raise the labor market participation would be focusing on the borders: visas should be issued mainly to the nationalities that are more willing to participate in the labor market. In the case of skill mismatch, instead, the policy options are more complex and may range from selective migration for immigrants whose characteristics are more compatible with the host country's needs to labor market policies aimed at educating and training workers to help them become more suited to local labor market requirements.

This paper relates to the very large literature on the assimilation of immigrants in the host labor markets. This literature aims at establishing two main facts: whether there is a gap in the labor market performances (in terms of wages, employment opportunities etc.) between natives and immigrants and how these evolve over time ${ }^{1}$.

Using German data Constant and Massey (2003) find that an assimilation process is at work: once in the host country, immigrants tend to start a process of human capital accumulation that reduce the gap with respect to natives; the authors, however, also highlight a significant disparity in wages between genders. In the UK, Clark and Lindley (2006) find a relevant heterogeneity among ethnic groups: non-white immigrants show a lower dynamics in wages compared with white immigrants. For Spain, AmuedoDorantes and de la Rica (2006) report a significant difference in the probability to be employed for immigrants: the employment gap is even larger when gender is accounted for, along with immigrants' origin.

However, the assimilation of immigrants has also relevant non-economic aspects. Bisin et al. (2008) show that Muslims integrate less with respect to non-Muslims in UK, a feature that appears to be smoothed, but still significant, in second-generation immigrants.

The role of culture has been particularly underlined in the analysis of economic assimilation of immigrant women. Compared with the native group, many studies (Dustmann and Schmidt, 2000; Constant et al., 2006; Bevelander and Groeneveld, 2007; Dustmann and Fabbri, 2005; Adsera and Chiswick, 2007) find that the probability to work for an immigrant woman is significantly lower even after controlling for observable characteristics. This is generally attributed to an unbalanced family burden and a cultural bias. Moreover, as Dustmann and Schmidt (2000) point out, the same motives also prevent women from accumulating human capital. By using the British Time Use Survey, Zaiceva and Zimmermann (2007) obtained a similar result for the UK and 
showed that non-white females usually spent more time in "traditional" duties such as religious activities and food management than white females. The poor labor market outcomes by foreign women is usually attributed to culture or religion. For the US, Fernandez and Fogli (2009) find that intergenerational transmission of cultural attitudes helps to explain the low contribution to the labor forces by second generation immigrant women. Vella (1994) obtains a similar result for educational choices. Heineck (2004) confirms the influence of religion, finding that the frequent attendance of places of worship reduces female participation in the labor market in Germany.

This paper aims at contributing to the literature on the effects of culture on the economic performance of immigrant women. However, compared with the previous literature, we aim at disentangling between demand (skill) and supply (cultural) components in the decision to participate in the labor market. This is a novelty since most of the existing papers just correlate the immigrant's cultural attitude to the labor market performance.

Our results show that culture has a low impact on the decision to work by immigrant women in Lombardy. Low activity and employment rates for certain national groups (mainly those from North African, the Middle East and central Asian) are involuntary since their estimated reservation wages are no greater than those of nationalities characterised by higher employment levels (for example, Central and Eastern Europeans) ${ }^{2}$.

The paper is organised as follows. Section 2 describes the ISMU dataset and shows some of the descriptive statistics; Section 3 explains the most relevant econometric issues; Section 4 presents the results; Section 5 concludes the paper. Appendix 1 shows how countries of origin are aggregated into clusters of nations while Appendix 2 presents a comparison between our estimated reservation wages and labor Force Survey (LFS) data.

\section{Data}

Our main data source is a dataset collected by the ISMU in Lombardy (with the financial support of the Lombardy regional government and other private institutions) in the period 2001-2005. Since 2001, the ISMU has conducted a yearly survey of immigrants living in Lombardy. As for migration studies, the dataset has a strong comparative advantage. Its most important characteristic is that it is also able to collect information for undocumented aliens due to its data-collection process based on the method of aggregation centres developed by Blangiardo (1993).

Survey design - Surveys on aggregation centres are specifically designed to collect information on a representative sample of immigrants that include also irregular migrants. The idea is that even undocumented individuals generally lead a social life by attending, for example, places of religious worship or cultural centres. Blangiardo's method hinges on those centres and is based on a three-stage design. In the first, the ISMU interviewers allocate the total number of questionnaires (roughly 8,000 each year) across the 11 provinces into which Lombardy is partitioned; this is aimed at obtaining significant estimates at provincial level by having roughly the same sample variability within each province. In the second stage, the ISMU selects a number of representative municipalities (slightly less than 350, almost 25 per cent of all the towns in Lombardy) in each province according to the social and economic characteristics of the area. In the third stage, the ISMU interviewers visit all possible 
aggregation centres for immigrants within each municipality and randomly meet the potential interviewees. The aggregation centres usually fall within 11 categories: help and counselling centres for immigrants, Italian language courses for foreigners, places of worship, healthcare centres, cultural centres, phone/money transfer centres, public offices (police stations, town halls, etc.), ethnic restaurants/bars, ethnic shopping centres, other (train stations, etc. ${ }^{3}$. Within each aggregation centre, the ISMU interviews usually have the support of the leading personalities of the centres (priests, shop owners etc.); this ensures that the interviewers are seen as "trusted" people and not public officials. As for the ability of the survey to truly detect irregular immigrants, the misreporting of legal status seems tiny. In order to provide a comparison between the ISMU estimates and actual data, we compare survey results with the most recent alternative dataset based on applications for regularization under the Bossi-Fini amnesty law of 2002. In that year, 144,369 individuals applied in Lombardy (647,000 in Italy as a whole): this indicates that at least the 31 per cent of the total foreign population in Lombardy was irregular in 2002. ISMU estimates for that year do not appear far off that figure: in the 2002 wave, self-declared illegal aliens represented 27 per cent of the sample.

Dataset description - This study uses five pooled waves from 2001 to 2005 . We concentrate on women of working age (i.e. the 15-64 cohorts), which leaves us with roughly 12 thousand individuals. The ISMU data contain information on social and economic characteristics. Table 1 presents the summary statistics for the variables used in the empirical analysis. Average schooling is quite high (10.7 years) ${ }^{4}$ and comparable with the figures for the Italian population. Almost 60 per cent of the interviewed women is married; they have been residing in Italy for a relatively short period of time (5.7 years). Irregular women make up 11.7 per cent of the total. As for religion, more than two thirds of the dataset is Catholic or Muslim. Other Christians (mainly Greek-Orthodox) are slightly more than one fifth of the sample. Table 1 also provides the distribution of immigrants according to the groups of country of origin (see Appendix 1 for the list of countries belonging to each group). Almost 30 per cent of the immigrant women come from European countries; sizeable groups are also constituted by Central and South Americans and people coming from the Near East and North Africa.

Standard figures on employment status are reported in Table $2,{ }^{5}$ which shows, as is usual in many industrialised countries, that there is considerable heterogeneity in labor market outcomes according to the country of origin. The employment rate averages 60 per cent for the entire sample, while the activity rate is much larger (73.4 per cent). The employment rate of the women coming from the Central and Eastern European Countries (CEEC) and Central and South America is roughly two-thirds higher than that for the Near East and North African countries (NENAC) ${ }^{6}$. The figure for the Central Asia group is even smaller. Activity rates display the same great variability across national groups.

Representativeness - A relevant concern for working on non-administrative data relates the representativeness of the dataset. In order to address this issue, we compare the main ISMU data characteristics with those of the labor Force Survey (LFS) for the North of Italy (where Lombardy is located and where most of the immigrants in Italy live, 2006-2008 averages) ${ }^{7}$. The main relevant difference between ISMU and LFS is in the country of origin composition: in LFS the share of women coming from CEEC is 
Table 1 Summary statistics of the main variables

\begin{tabular}{|c|c|c|c|}
\hline & No. Obs. & Sample mean & Std. Dev. \\
\hline School & 11,852 & 10.746 & 4.541 \\
\hline Potential Experience & 11,852 & 16.764 & 9.295 \\
\hline Years in Italy & 11,989 & 5.734 & 4.610 \\
\hline Net monthly wage & 9,988 & 606.874 & 1214.336 \\
\hline Children below 18yrs & 12,015 & 0.696 & 0.990 \\
\hline Children above 18yrs & 12,015 & 0.527 & 1.566 \\
\hline Married & 12,015 & 0.569 & 0.495 \\
\hline Family network & 4,851 & 0.358 & 0.479 \\
\hline Family reunification visa & 9,914 & 0.226 & 0.441 \\
\hline Irregular & 12,015 & 0.117 & 0.321 \\
\hline & No. Obs. & \multicolumn{2}{|c|}{ Percentages } \\
\hline \multicolumn{4}{|l|}{ Religions: } \\
\hline Catholic & 12,015 & \multicolumn{2}{|c|}{38.33} \\
\hline Muslim & 12,015 & \multicolumn{2}{|c|}{30.89} \\
\hline Other Christians & 12,015 & \multicolumn{2}{|c|}{18.46} \\
\hline Buddhists & 12,015 & \multicolumn{2}{|c|}{3.21} \\
\hline Hindu & 12,015 & \multicolumn{2}{|c|}{1.35} \\
\hline Other & 12,015 & \multicolumn{2}{|c|}{2.24} \\
\hline No creed & 12,015 & \multicolumn{2}{|c|}{5.52} \\
\hline \multicolumn{4}{|l|}{ Groups of countries of origin: } \\
\hline Central and Eastern European Countries & 12,015 & \multicolumn{2}{|c|}{28.56} \\
\hline Central or Southern America & 12,015 & \multicolumn{2}{|c|}{19.55} \\
\hline Near East and North Africa & 12,015 & \multicolumn{2}{|c|}{18.29} \\
\hline Sub-Saharan Africa & 12,015 & \multicolumn{2}{|c|}{15.59} \\
\hline East Asia & 12,015 & \multicolumn{2}{|c|}{12.44} \\
\hline Central Asia & 12,015 & \multicolumn{2}{|c|}{5.57} \\
\hline
\end{tabular}

Source: Authors' calculations on ISMU dataset.

54 percent, 20 percentage points greater than the ISMU figure. The difference between the two sources is quite sizeable and this could raise some issues related to the external validity of the analyses. However, it should be noted that all other population characteristics are quite similar. The average schooling is 10.2 years in the LFS. The activity rate is slightly lower (65 per cent) probably due to the different definitions of working status between LFS

Table 2 Activity and employment rates across national groups

\begin{tabular}{ccc}
\hline & Activity rate & Employment rate \\
\hline Central and Eastern European Countries & 82.0 & 70.1 \\
Central or Southern America & 86.9 & 73.9 \\
Near East and North Africa & 49.7 & 41.4 \\
Sub-Saharan Africa & 78.3 & 66.0 \\
East Asia & 77.1 & 71.1 \\
Central Asia & 38.2 & 29.8 \\
Total & $\mathbf{7 3 . 4}$ & $\mathbf{6 2 . 8}$ \\
\hline
\end{tabular}

Source: Authors' calculations on ISMU dataset.

Activity and employment rates are computed on self-declared working status. Averages weighted according to the sample design. 
and ISMU. More importantly the labor market access differences among groups are preserved, for example the NENAC group in the LFS survey still maintain a huge gap in the activity rate in comparison with CEEC group (20 percentage points).

\section{Empirical approach}

\subsection{How do economists obtain reservation wages?}

The aim of this paper is to report an econometric estimate of the immigrants' reservation wages. In job search theory, the reservation wage is the lowest offered wage that an unemployed individual looking for work is prepared to accept (see Blundell and MaCurdy, 1999) ${ }^{8}$. Although this is a crucial variable in the neoclassical theory of labor supply, there is still an open discussion on the best way to estimate it. Two prevailing methods are usually available in literature.

The first is based upon surveys in which unemployed respondents are directly asked what their reservation wage is ${ }^{9}$. This information is widely used in many studies: see, among others, Addison et al. $(2004,2010)$ and, for the Italian case, Sestito and Viviano (2011). The reliability of this information, however, is widely debated. As shown by Burdett and Vishwanath (1988) and Hofler and Murphy (1994), self-reported reservation wages are often biased and they are usually inconsistent with the actual behaviour of a worker. As Addison et al. (2010) point out, this is mainly due to the fact that respondents usually answer by indicating the prevailing wage on the labor market, rather than their true reservation value.

The second method treats reservation wages as unobservables, that must be inferred econometrically by the actual behaviour of a worker. This was pioneered by Heckman (1974) in his contribution on women's shadow prices in the labor market and was subsequently developed in further studies (see, Kiefer and Neumann, 1979, 1981; Fishe, 1982; Ferber and Green, 1985; Duncan, 1992; Sharpe and Abdel-Ghany, 1997). The idea is that observed wages for employed individuals are those that succeed in exceeding the individual reservation values. This implies that, by controlling for the selectivity bias, actual market wages contain enough information to infer workers' reservation wages ${ }^{10}$.

In this paper we adopt the second methodology for two main reasons. The first relates upon the above-mentioned reliability problems of self-reported reservation wages - problems that can be greatly aggravated for migrants, whose understanding of the crucial features of the local labor market is more limited. The second relates to the availability of sufficient observations in the LFS. In Appendix 2 we provide the results for self-reported reservation wages in the Italian LFS. By concentrating on immigrants living in the North, we end up with just under 1,000 individuals, which is one-tenth of our baseline estimation sample.

The methodology we use in this paper is based on the Mohanty's (2005) extension of the Heckman model with frictional unemployment and feedbacks between labor demand and supply. As will soon be clearer, from a technical point of view, the only difference between this methodology and Heckman's lies in the first stage, which is bivariate-probit rather than probit estimated. This allows us to take into account a double selectivity bias due to involuntary unemployment or feedback effects between demand and supply ${ }^{11}$. 


\subsection{The estimate of reservation wages: an econometric approach}

A woman $i$ decides to participate in the labor market (i.e. to be active) whenever the wage offers she expects to receive are greater than her own reservation wage. In formulas, this implies that she is active whenever $\mathrm{w}_{\mathrm{i}}^{0}-\mathrm{w}_{\mathrm{i}}^{\mathrm{r}}=\mathrm{y}_{1 \mathrm{i}} \geq 0$, where $\mathrm{w}^{\mathrm{o}}{ }_{\mathrm{i}}$ is the expected wage offer, $w_{i}^{r}$ is her reservation wage and $y_{1 i}$ represents the (normalised) individual preference for labor market participation. Whenever $y_{1 i}$ is greater than zero, individual $i$ participates to the labor market, whenever it is negative she prefers to stay at home. It immediately follows that reservation wages can be obtained as $\mathrm{w}_{\mathrm{i}}^{\mathrm{r}}=\mathrm{w}_{\mathrm{i}}^{0}-\mathrm{y}_{1 \mathrm{i}}$ and can be computed by estimating preferences $\left(\mathrm{y}_{1 \mathrm{i}}\right)$ and wage offers $\left(\mathrm{w}_{\mathrm{i}}^{\mathrm{o}}\right)$.

Estimates for $\mathrm{y}_{1 \mathrm{i}}$ and $\mathrm{w}_{\mathrm{i}}^{\mathrm{o}}$ are obtained in two steps.

In the first step we consider both the participation decision and the hiring process in the labor market. Woman $i$ is employed only if she decides to participate in the labor market $\left(\right.$ Participate $\left._{i}=1\right)$ and is hired by an employer $\left(\right.$ Employed $\left._{i}=1\right)$. Formally,

$$
\text { Participate }_{i}= \begin{cases}1 & \text { if } y_{1 i} \geq 0 \\ 0 & \text { if } y_{1 i}<0\end{cases}
$$

and

$$
\text { Employed }_{i}= \begin{cases}1 & \text { if } y_{2 i} \geq 0 \\ 0 & \text { if } y_{2 i}<0\end{cases}
$$

where $y_{2 \mathrm{i}}$ represents the (normalised) employers' preferences over individual $i$.

The aim of the first step is to compute the latent variables $y_{1}$ and $y_{2}$ by estimating the following two equations:

$$
\begin{aligned}
& y_{1}=x_{1} b_{1}+e_{1} \\
& y_{2}=x_{2} b_{2}+e_{2}
\end{aligned}
$$

by a bivariate probit with partial observability. The choice of the bivariate probit is particularly useful since it allows us to treat demand and supply components simultaneously. As mentioned above, this allows us to take into account the existence of feedbacks between the decision to participate and the expected labor market outcome. Operationally, $\mathrm{x}_{1}$ contains a set of variables aimed at capturing the economic and cultural determinants for the labor supply, while $\mathrm{x}_{2}$ includes all the possible personal characteristics which are likely to influence the employer's willingness to hire an individual.

As for the supply components, $\mathrm{x}_{1}$ includes schooling, potential experience, religion dummies and their interaction with marital status, number of children below and above 18 years of age and a set of time dummies. The number of under age children may indicate a greater interest for childcare and housekeeping while the number of children over 18 should have a positive effect on the labor supply since offspring could need financial support from the family of origin. Religion dummies indicate a cultural attitude toward labor, especially when a woman is married. As will be clear later, religion dummies play a fundamental role as identification variables in the empirical strategy.

On the demand side, $\mathrm{x}_{2}$ contains schooling, years since migration, dummies for country of origin, time, and space ${ }^{12}$. Years since migration are expected to enhance the probability for a worker to be employed since during these years the worker is likely to increase his ability to understand the crucial features of the host country's labor market and local language; ${ }^{13}$ country dummies capture the workers' heterogeneity in terms of 
the quality of the institutions in their area of origin (for example, educational system, sectoral specialization) while spatial dummies capture time invariant local characteristics that are likely to influence employment levels.

$\mathrm{x}_{1}$ and $\mathrm{x}_{2}$ share the schooling variable and time dummies, since education is likely to have an effect on both the demand and supply components and year dummies take into consideration business cycle fluctuations.

The latent variable of interest $\left(\hat{y}_{1}\right)$ is calculated by taking the predicted values (linear prediction) of equation (1).

In the second step, we compute expected wage offers. We estimate the following wage equation using a correction for a double selectivity bias (Tunali, 1986):

$$
\ln w_{i}^{m}=\alpha+b_{3} x_{3}+c_{13} \lambda_{1 i}+c_{23} \lambda_{2 i}+D_{s}+D_{t}+D_{c}+u_{i}
$$

where $u_{i}=\varepsilon_{i}-c_{13} \lambda_{1 i}-c_{23} \lambda_{2 i}, \lambda_{1 i}=\frac{\phi\left(x_{1 i} b_{1}\right) \Phi\left(\frac{x_{2 i} b_{2}-\rho x_{1} b_{1}}{\sqrt{1-\rho^{2}}}\right)}{F\left(x_{1 i} b_{1}, x_{2 i} b_{2}, \rho\right)}$ and $\lambda_{2 i}=\frac{\phi\left(x_{2 i} b_{2}\right) \Phi\left(\frac{x_{1 i} b_{1}-\rho x_{2} b_{2}}{\sqrt{1-\rho^{2}}}\right)}{F\left(x_{1 i} b_{1}, x_{2 i} b_{2}, \rho\right)}$. $\phi$ and $\Phi$ represent, respectively, the density and the cumulative function of a univariate standard normal distribution, $\mathrm{F}$ denotes the bivariate standard normal distribution, while $\rho$ (rho) is the correlation of the error terms in the bivariate probit. $x_{3}$ includes standard variables in migration-augmented mincerian equations: schooling, potential experience and years since migration. The regression includes spatial dummies $\left(D_{s}\right)$ to take into account spatial differences in wage levels; time dummies $\left(D_{t}\right)$ to control for business cycle effects. Country of origin dummies $\left(D_{c}\right)$ control for institutional factors such as educational quality (inserting area dummies deliver very similar results).

Expected wage offers are computed as follows:

$$
\hat{w}^{0}=\exp \left(\ln \hat{w}^{m}\right)
$$

Where $\left(\ln \hat{w}^{m}\right)$ is the predicted value of equation (3). $\hat{w}^{o}$ represents the expected market wage conditional on the individual characteristics and controlling for the selectivity bias due to participation and hiring decisions ${ }^{14}$.

Reservation wages can now be calculated as $\hat{w}^{r}=\hat{w}^{0}-\hat{y}_{1}$ for all the individuals in the sample.

By comparing all the variables in $x_{1}, x_{2}$ and $x_{3}$, the crucial role of religion dummies and their interaction with marital status as identification variables is now apparent. The idea is that religion is a private matter that affects the individual working decisions but should not affect the labor market evaluation (wages) and the hiring decision by a nondiscriminating employer. In other words, the worker's productivity should be influenced by the country of origin's institutional setting (school quality, sectoral specialization etc.) but not by the migrant's private attitudes toward religion (which does, however, influence her decision to work). This implies that by inserting country dummies in equations (2) and (3) we estimate a supply effect that is within-country and across religions. This can be done only if we have an imperfect overlap between religions and countries of origin, i.e. when there are different religious creeds within a country. In order to have a suitable sample for this identification we exclude all individuals coming from a country where, according to the ISMU dataset, only one creed is professed. The list of a diversification indicator of religions (Herfindhal index: $\mathrm{HI}^{15}$ ) in each country is 
provided in Appendix 1; the higher HI the less diverse the country; in all the analyses we exclude all countries with a HI equal to one.

A possible challenge to the identification of equations (1), (2) and (3) is the presence of occupations in which foreigners coming from the same nation tend to cluster (Patel and Vella, 2007). This would invalidate the cross-country comparison since reservation wages are driven by cross-nation sector of specialization and the mobility is low. Ideally, this would be solved by inserting sector dummies in equation (3); however, in this case the computation of wage offers for not-employed immigrants would be impossible since predicted values cannot be calculated for unemployed and inactive. It should be noted, however, country dummies in equation (2) and (3) take also into account differentiated search networks and their effects on wages, thus limiting the relevance of these concerns. In a robustness check, we calculate reservation wages for employed individuals by inserting sector dummies with results much in line with the one presented here ${ }^{16}$.

\subsection{Cross-country differences and robustness}

After computing the reservation wages, we test whether they systematically differ across groups of nationalities. We calculate the percentage differences between each group and a reference cluster. Our first choice would have been native women. However since the ISMU dataset only concentrates on immigrants, we chose the CEEC (Central and Eastern European Countries) group. The choice of CEEC as a benchmark relies on the fact that they share similar institutions with the host country and are generally seen as a reference group in the assimilation patterns in most countries ${ }^{17}$. We focus on the differences between the CEEC group and two nationalities that display the lowest activity and employment rates: NENAC and Central Asia. If the reservation wages for those groups were higher, the observed low labor market participation would be interpreted as voluntary: the value NENAC and Central Asian women attach to their time spent at home is so high that they are not attracted by the local labor market. Conversely, if their reservation wages were comparable or lower to that of our reference group, their inactive status would be interpreted as involuntary: their reservation values are not particularly high but they remain unemployed because the arrival rate of job offers is quite low.

We further check the robustness of these estimates along four lines.

The first check is based on Italian migration law according to which it is necessary to have a job in order to obtain a visa. As an exception to this rule, immigrants can enter Italy to join their family and obtain a visa based on family reunification. For those cases, migrants' true shadow values should be revealed since they do not need to work to obtain a residence permit. We check this issue by restricting the analysis to those women who migrated to Italy with a family reunification visa. This information is available for all years except for 2004: migrants entering the country for with a family reunification visa amount to 2,408 .

The previous scheme obviously implies that the immigrants have a good knowledge of the Italian migration laws. We can generalise it by focussing on migrants with a blood relative already residing in the country at migration time. Again, for those individuals their shadow values could be higher, since they can rely on the family's financial support while looking for work. We check this issue by restricting the analysis to 
women who entered the country when a next of kin was already residing here. This leaves us with 1,753 individuals.

The third check is based on the analysis of the irregular migrants. Undocumented aliens have very weak bargaining power with respect to their employers as they cannot join a union and must work off the books. This implies that wage offers are usually quite low (Accetturo and Infante, 2010) and, therefore, they may be quite close to the reservation wages. Moreover, illegal aliens' incentives to work are particularly strong since their only chance of being regularised under one of the recurrent amnesties is strictly linked to evidence that they are employed on Italian soil. In other words, they are more likely to accept the jobs they are offered. In the ISMU dataset, irregular women are surveyed each year and they amount to 1,303 individuals.

The fourth check is based on the relationship between religions and countries. As we said before, we already discard all the observations coming from one-religion countries. However, in some countries a religion could prevail but not be the only one (for example, Islam in Arab countries or Roman Catholicism in Central and South America); this implies that from the employer's point of view religions and countries of origin are quite indistinguishable thus invalidating our identification structure. We cope with this problem by restricting our analysis to a group of countries that can be considered truly multi-religious. This is done by discarding all observations coming from countries whose $\mathrm{HI}$ based on religions exceeds 0.75 : this leaves us with 8,305 individuals.

\section{Results}

\subsection{Baseline sample}

The first part of this section is devoted to the results of the baseline sample. This group is constituted by all the regular women of working age interviewed in the 2001-2005 waves.

Table 3 shows the results of both the bivariate probit estimates (columns [1] and [2]) and the wage equation (column [3]). As expected, schooling positively affects the probability to be active and to be employed in the labor market. Moreover, potential experience increases the probability to supply labor and the years spent in Italy increases the likelihood to be employed. The number of children below (above) 18 years old reasonably raise (decrease) the probability to be active. Estimates also show that the correlation among error terms (rho) is quite high ${ }^{18}$.

In the second step, we estimate a classical wage equation for all working individuals and we take into account the possible selection bias by plugging the computed $\lambda_{1}$ and $\lambda_{2}$ into the equation. Results are displayed in column [3]. All variables have the expected sign and are significant. The highly significant coefficients of $\lambda_{1}$ and $\lambda_{2}$ imply that selection is at work. The use of estimated values of columns [1] and [3] allows us to compute reservation wages.

Before starting with the comparison across national groups it is worth assessing whether estimated reservation wages are consistent with the predictions of the standard theory of labor supply (Table 4). As Blundell and MaCurdy (1999) point out, individuals with a higher inter-temporal elasticity of substitution should have lower reservation wages: this is confirmed in our estimates since younger individuals attach a lower economic value to time spent at home compared with older cohorts. Even education plays an important role in setting the individual's reservation value. Consistently with the 
Table 3 Baseline sample

\begin{tabular}{|c|c|c|c|}
\hline & [1] & [2] & \\
\hline & \multicolumn{2}{|c|}{ Biprobit estimates } & \multirow{2}{*}{$\begin{array}{l}\text { Wage equation } \\
\text { Dependent variable: } \\
\text { Net monthly wage }\end{array}$} \\
\hline & $\begin{array}{l}\text { Dependent } \\
\text { variable: } \\
\text { Participate }\end{array}$ & $\begin{array}{l}\text { Dependent } \\
\text { variable: } \\
\text { Employed }\end{array}$ & \\
\hline \multirow[t]{2}{*}{ School } & $0.039^{* * *}$ & $0.024^{* * *}$ & $0.007^{* * *}$ \\
\hline & $(0.004)$ & $(0.004)$ & $(0.001)$ \\
\hline \multirow[t]{2}{*}{ Potential experience } & $0.043^{* * *}$ & - & $0.009^{* * *}$ \\
\hline & $(0.005)$ & & $(0.002)$ \\
\hline \multirow[t]{2}{*}{ 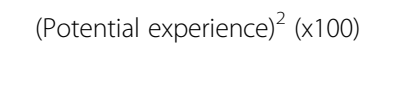 } & $-0.069^{* * *}$ & - & $-0.021^{* * *}$ \\
\hline & $(0.011)$ & & $(0.000)$ \\
\hline \multirow[t]{2}{*}{ Years in Italy } & - & $0.101^{* * *}$ & $0.016^{* * *}$ \\
\hline & & $(0.009)$ & $(0.005)$ \\
\hline \multirow[t]{2}{*}{$(\text { Years in Italy) })^{2}(x 100)$} & - & $-0.415^{* * *}$ & $-0.047^{*}$ \\
\hline & & $(0.051)$ & $(0.025)$ \\
\hline \multirow[t]{2}{*}{ Children below 18yrs } & $0.045^{* *}$ & - & $-0.058^{* * *}$ \\
\hline & $(0.021)$ & & $(0.007)$ \\
\hline \multirow[t]{2}{*}{ Children above 18yrs } & $-0.088^{* * *}$ & - & $-0.022^{* * *}$ \\
\hline & $(0.016)$ & & $(0.006)$ \\
\hline \multirow[t]{2}{*}{ Marital status } & $-0.554^{* * *}$ & - & $-0.046^{* *}$ \\
\hline & $(0.066)$ & & $(0.014)$ \\
\hline Spatial dummies & NO & Local labor system & Local labor system \\
\hline Year dummies & YES & YES & YES \\
\hline $\begin{array}{l}\text { Religion dummies and their } \\
\text { interaction with the marital status }\end{array}$ & YES & NO & NO \\
\hline Country of origin dummies & NO & YES & YES \\
\hline \multirow[t]{2}{*}{ Lambda1 } & - & - & $-0.171^{* *}$ \\
\hline & & & $(0.068)$ \\
\hline \multirow[t]{2}{*}{ Lambda2 } & - & - & $-0.163^{* *}$ \\
\hline & & & $(0.074)$ \\
\hline \multirow[t]{2}{*}{ Intercept } & $0.231^{* *}$ & $-0.492^{* * *}$ & $7.100^{* * *}$ \\
\hline & $(0.103)$ & $(0.119)$ & $(0.089)$ \\
\hline Rho & \multicolumn{2}{|c|}{0.916} & - \\
\hline No. Obs. & \multicolumn{2}{|c|}{10,459} & 5,937 \\
\hline
\end{tabular}

Source: Authors' calculations on ISMU dataset.

Robust standard errors in parenthesis. Wage equation standard error take into account the two-step procedure. Stars show significance levels, ${ }^{* *}$ up to 1 per cent, ${ }^{* *}$ between 1 per cent and 5 per cent, * between 5 per cent and 10 per cent. All regressions are weighted according to the sample design.

standard theory, we find that more educated individuals usually set higher reservation wages. Finally we check whether individuals residing in a city ${ }^{19}$ have a lower reservation value because of lower job-search costs thanks to better access to the transportation network. This is confirmed by the bottom panel, in which we show reservation wages for workers in a city by educational group.

How reasonable are these estimates? We compare our measure of reservation wage with self reported value (as it appears in the Italian LFS, see Table 5): the results are surprisingly similar. In particular, NENAC and Central Asia groups still have a tendency toward a low 
Table 4 Estimated reservation wages: standard properties (baseline sample)

\begin{tabular}{|c|c|}
\hline All individuals & 780.86 \\
\hline \multicolumn{2}{|l|}{ Age: } \\
\hline$<25$ & 746.47 \\
\hline $25-29$ & 767.43 \\
\hline $30-34$ & 795.95 \\
\hline $35-39$ & 796.18 \\
\hline$>39$ & 778.07 \\
\hline \multicolumn{2}{|l|}{ Years of schooling: } \\
\hline$<8$ & 682.24 \\
\hline $8-12$ & 780.25 \\
\hline $13-16$ & 786.96 \\
\hline$\geq 17$ & 820.88 \\
\hline \multicolumn{2}{|c|}{ Years of schooling in a city: } \\
\hline$<8$ & 677.69 \\
\hline $8-12$ & 765.09 \\
\hline $13-16$ & 778.79 \\
\hline$\geq 17$ & 816.54 \\
\hline
\end{tabular}

Source: Authors' calculations on ISMU dataset.

Means are weighted according to the sample design.

A woman is considered to be living in a city if she resides in one of the towns belonging to the local labor markets of Milan, Brescia and Bergamo.

rank. Our benchmark group reports the highest reservation wage, still with a high participation ratio to the labor market.

We subsequently deal with the core estimates of the paper. In Table 6 we analyse the reservation wages and their differences across national groups. Columns [1] and [2] show the activity and employment rates for the baseline sample (regular aliens) ${ }^{20}$ the last column reports the percentage difference of the reservation wage of a national group with respect to the CEEC.

Estimates show that while the share of active and working population is substantially low for the NENAC and Central Asia group, their reservation wages are statistically smaller than those computed for the CEEC group. This suggests that low participation should not be attributed to a cultural attitude that raises the economic value of the time spent at home, but, rather, to a skill mismatch between local labor market requirements and immigrants' abilities.

Table 5 Comparison between Ifs and our estimates

\begin{tabular}{ccc}
\hline & {$[\mathbf{1}]$} & [2] \\
& LFS & Our estimates \\
\hline Central and Eastern European Countries & 832.93 & 780.03 \\
Central or Southern America & 816.22 & 797.43 \\
Near East and North Africa & 728.55 & 754.16 \\
Sub-Saharan Africa & 731.42 & 811.01 \\
East Asia & 741.45 & 781.28 \\
Central Asia & 788.53 & 715.12 \\
\hline
\end{tabular}

Source: Authors' calculations on LFS and ISMU dataset. 
Table 6 Reservation wage differences across nationalities (baseline sample)

\begin{tabular}{cccc} 
& $\begin{array}{c}{[\mathbf{1}]} \\
\text { Activity } \\
\text { rate }\end{array}$ & $\begin{array}{c}\text { [2] } \\
\text { Employment } \\
\text { rate }\end{array}$ & $\begin{array}{c}\text { [3] } \\
\text { Reservation wages (1) }\end{array}$ \\
\hline $\begin{array}{c}\text { Central and Eastern European } \\
\text { Countries }\end{array}$ & 79.8 & 69.9 & $\begin{array}{c}\text { Percentage difference with respect to the } \\
\text { CEEC group: }\end{array}$ \\
Central or Southern America & 85.3 & 73.4 & $0.029^{* * *}$ \\
Near East and North Africa & 47.0 & 40.5 & $(0.006)$ \\
Sub-Saharan Africa & 76.4 & 66.6 & $-0.096^{* * *}$ \\
& & & $(0.007)$ \\
East Asia & 76.9 & 71.2 & -0.003 \\
& & & $(0.007)$ \\
Central Asia & 35.1 & 27.5 & $0.045^{* * *}$ \\
No. Obs. & & & $(0.009)$ \\
\hline
\end{tabular}

Source: Authors' calculations on ISMU dataset.

(1) Percentage differences in computed reservation wages. Stars show significance levels, *** up to 1 per cent, ** between 1 per cent and 5 per cent, ${ }^{*}$ between 5 per cent and 10 per cent. Mean differences are weighted according to the sample design.

We further split the computed reservation wages across educational levels and years since migration.

Table 7 shows the differentiated effects across four classes of education: no education, primary, secondary and tertiary schooling. Baseline results are confirmed as reservation wages for NENAC and Central Asian are always statistically lower than the estimate for the CEEC. In columns [1] to [4] of Table 8 we report the percentage differences in reservation wages for subgroups belonging to (respectively) the first to the fourth quartile of the distribution of years since migration. Even in this case the results remain undisputed.

\subsection{Robustness}

So far we have obtained the interesting result that the low employment/activity rates registered for certain groups are not associated with higher reservation wages.

In this section we present four robustness checks by restricting the analysis to: (i) women benefitting from a visa based on family reunification, (ii) immigrants with a blood relative at the time of migration to the host country, (iii) undocumented immigrants, and (iv) immigrants coming from truly multi-religious countries.

Results for the first check are shown in Table 9. Columns [1] and [2] report, respectively, the shares of active and working population among those who entered with a family reunification visa: consistently with the standard theory of labor supply, activity and employment rates are quite small now, thus reflecting their possibility to sustain larger spells of unemployment; ${ }^{21}$ however, there are still differences across national groups. In column [3] we report the estimated reservation wage. Baseline results are still confirmed: NENAC and Central Asia are among the lowest participant group in the labor market, while the reservation wage in this subsample is also the lowest for 
Table 7 Reservation wage differentials across educational levels (baseline sample)

\begin{tabular}{ccccc}
\hline & $\begin{array}{c}{[1]} \\
\text { No formal } \\
\text { education }\end{array}$ & $\begin{array}{c}\text { [2] } \\
\text { Compulsory } \\
\text { school }\end{array}$ & $\begin{array}{c}\text { [3] } \\
\text { Secondary } \\
\text { education }\end{array}$ & $\begin{array}{c}\text { Tertiary } \\
\text { education }\end{array}$ \\
\hline $\begin{array}{c}\text { Percentage difference with respect to } \\
\text { the CEEC group: }\end{array}$ & & & & \\
Central or Southern America & 0.054 & $0.042^{* * *}$ & $0.022^{* *}$ & -0.002 \\
Near East and North Africa & $(0.038)$ & $(0.014)$ & $(0.009)$ & $(0.015)$ \\
Sub-Saharan Africa & -0.021 & $-0.026^{*}$ & $-0.082^{* * *}$ & $-0.074^{* * *}$ \\
& $(0.027)$ & $(0.013)$ & $(0.010)$ & $(0.016)$ \\
East Asia & $0.052^{*}$ & $0.071^{* * *}$ & $0.040^{* * *}$ & $-0.075^{* * *}$ \\
& $(0.029)$ & $(0.014)$ & $(0.011)$ & $(0.020)$ \\
Central Asia & -0.040 & -0.001 & $0.026^{* *}$ & 0.011 \\
& $(0.042)$ & $(0.014)$ & $(0.012)$ & $(0.015)$ \\
No. Obs. & -0.039 & $-0.102^{* * *}$ & $-0.116^{* * *}$ & $-0.137^{* * *}$ \\
& $(0.033)$ & $(0.018)$ & $(0.017)$ & $(0.033)$ \\
\hline
\end{tabular}

Source: Authors' calculations on ISMU dataset.

Percentage differences in computed reservation wages. Stars show significance levels, *** up to 1 per cent, ${ }^{* *}$ between 1 per cent and 5 per cent, ${ }^{*}$ between 5 per cent and 10 per cent. Mean differences are weighted according to the sample design.

the Central Asian women, and statistically equivalent to the benchmark group for the NENAC women. A very similar picture is depicted in Table 10, which shows the estimates for immigrants with a blood relative already residing in Italy.

Estimates for the irregulars are reported in Table 11. Columns [1] and [2] (activity and employment rates) show that incentives to work are particularly strong for the irregulars. Activity rate averages around 90 per cent, while the employment rate is much lower (64 per cent). Cross-national differences are still in place, especially in the employment rates, although they narrow with respect to the baseline sample. However, our baseline result on reservation wages remains undisputed: the difference in reservation wages is negative and statistically significant for the NENAC group, while negative but not significant for Central Asian migrants.

Finally, Table 12 tackles the issue of the multi-religious countries. As explained above, even in nations with an HI based on religions smaller than one, we can observe the prevalence of one religion that can invalidate our identification strategy. To address this concern, we only consider countries with an HI lower than 0.75 . Results remain quite similar to the baseline ones, thus confirming the correctness of the identification strategy.

\section{Concluding remarks}

As in many advanced countries, activity and employment rates for immigrant women in Italy display great variability across nationals groups. Some nationalities (NENAC, Central Asia), in particular, are characterised by extremely low participation in the labor market. This fact can be due to either a supply "cultural" or a demand "skill" effect. The aim of this paper is to disentangle these two components by estimating the economic value of the time spent at home (reservation wages). 
Table 8 Reservation wage differentials across years since migration (baseline sample)

\begin{tabular}{ccccc}
\hline & $\begin{array}{c}{[1]} \\
\text { Less than } \mathbf{3} \\
\text { years }\end{array}$ & $\begin{array}{c}{[\mathbf{2}]} \\
\mathbf{3} \text { to } \mathbf{5} \\
\text { years }\end{array}$ & $\begin{array}{c}\mathbf{5} \text { to } \mathbf{8} \\
\text { years }\end{array}$ & $\begin{array}{c}\text { More than } 8 \\
\text { years }\end{array}$ \\
\hline $\begin{array}{c}\text { Percentage difference with respect to the CEEC } \\
\text { group: }\end{array}$ & & & & \\
Central or Southern America & 0.017 & 0.008 & 0.015 & $0.030^{* *}$ \\
Near East and North Africa & $(0.017)$ & $(0.013)$ & $(0.013)$ & $(0.015)$ \\
Sub-Saharan Africa & $-0.063^{* * *}$ & $-0.064^{* * *}$ & $-0.120^{* * *}$ & $-0.064^{* * *}$ \\
East Asia & $(0.016)$ & $(0.013)$ & $(0.012)$ & $(0.015)$ \\
& 0.030 & $-0.040^{* * *}$ & $-0.045^{* * *}$ & $0.061^{* * *}$ \\
Central Asia & $(0.019)$ & $(0.015)$ & $(0.013)$ & $(0.015)$ \\
& -0.029 & 0.010 & -0.022 & 0.008 \\
No. Obs. & $(0.021)$ & $(0.016)$ & $(0.015)$ & $(0.015)$ \\
& $-0.071^{* * *}$ & $-0.171^{* * *}$ & $-0.159^{* * *}$ & $-0.104^{* * *}$ \\
\hline
\end{tabular}

Source: Authors' calculations on ISMU dataset.

Percentage differences in computed reservation wages. Stars show significance levels, *** up to 1 per cent, ${ }^{* *}$ between 1 per cent and 5 per cent, ${ }^{*}$ between 5 per cent and 10 per cent. Mean differences are weighted according to the sample design.

From a technical point of view, we use religion as an identification variable for the effects of culture on labor supply in multi-religious countries. Our results show that low activity and employment rates for NENAC and Central Asia are not associated with higher reservation wages; this implies that low migrant participation is attributable to a weak demand for their skills rather than to a high value ascribed to time spent at home.

Table 9 Robustness check: family reunification visa

\begin{tabular}{|c|c|c|c|}
\hline & $\begin{array}{l}\text { [1] } \\
\text { Activity } \\
\text { rate }\end{array}$ & $\begin{array}{l}\text { [2] } \\
\begin{array}{l}\text { Employment } \\
\text { rate }\end{array}\end{array}$ & $\begin{array}{c}\text { [3] } \\
\text { Reservation wages (1) }\end{array}$ \\
\hline & & & $\begin{array}{l}\text { Percentage difference with respect to the } \\
\text { CEEC group: }\end{array}$ \\
\hline $\begin{array}{c}\text { Central and Eastern European } \\
\text { Countries }\end{array}$ & 54.4 & 42.8 & \\
\hline \multirow[t]{2}{*}{ Central or Southern America } & 68.1 & 55.3 & $0.067^{* * *}$ \\
\hline & & & $(0.023)$ \\
\hline \multirow[t]{2}{*}{ Near East and North Africa } & 27.0 & 22.6 & 0.015 \\
\hline & & & $(0.016)$ \\
\hline \multirow[t]{2}{*}{ Sub-Saharan Africa } & 52.8 & 47.5 & 0.025 \\
\hline & & & $(0.020)$ \\
\hline \multirow[t]{2}{*}{ East Asia } & 53.0 & 50.5 & -0.025 \\
\hline & & & $(0.021)$ \\
\hline \multirow[t]{2}{*}{ Central Asia } & 28.6 & 16.5 & $-0.063^{* * *}$ \\
\hline & & & $(0.022)$ \\
\hline No. Obs. & & & 2,408 \\
\hline
\end{tabular}

Source: Authors' calculations on ISMU dataset.

(1) Percentage differences in computed reservation wages. Stars show significance levels, *** up to 1 per cent, ** between 1 per cent and 5 per cent, * between 5 per cent and 10 per cent. Mean differences are weighted according to the sample design. 
Table 10 Robustness check: family ties

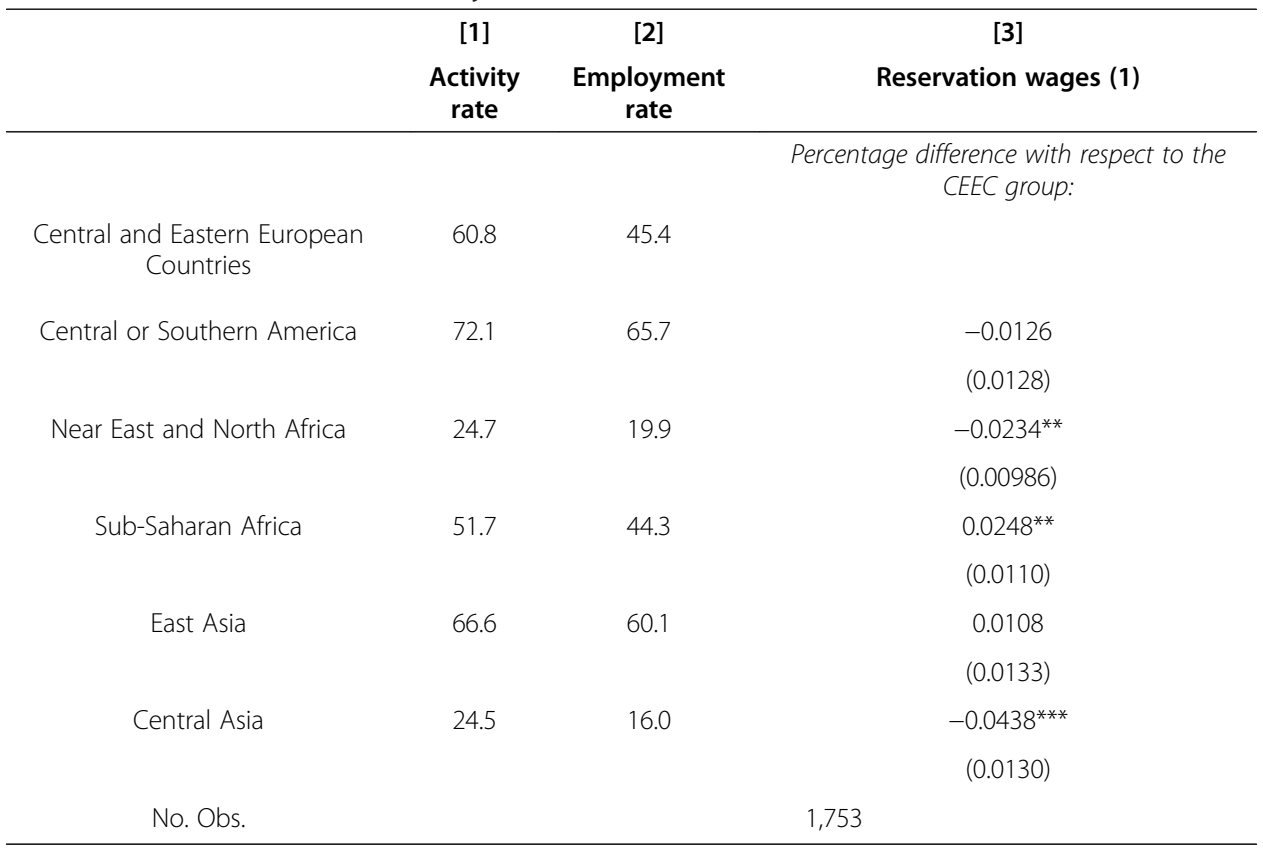

Source: Authors' calculations on ISMU dataset.

(1) Percentage differences in computed reservation wages. Stars show significance levels, *** up to 1 per cent, ** between 1 per cent and 5 per cent, * between 5 per cent and 10 per cent. Mean differences are weighted according to the sample design.

This result is quite robust to a number of sample selections and specification tests. In particular, the reservation wage differentials do not change according to the mode of entry into the host country (visa based on family reunification or the presence of blood relatives) or to legal status within the host country.

This result can hardly be overlooked and it may have some important policy implications. As low participation is mainly involuntary, policymakers have a set of policies that can be used to raise participation and employment rates. The first option is related to selective migration. As far as the policymakers are concerned, with a quantitative target (e.g. Lisbon criteria), admissions could be aimed at those nationalities whose capabilities to integrate are particularly high. The policy, in this case, could also be designed to require different educational levels for different countries of origin. Alternatively, for the nationalities whose skills are particularly mismatched, the policymaker can think of stricter educational requirements. The second set of options relates to policies for labor market inclusions. The idea is to create a set of training programmes with the aim of helping immigrants to become more suited to local labor market requirements.

\section{Endnotes}

${ }^{1}$ The literature on the assimilation of migrants is actually huge. Past and more relevant contributions are Chiswick (1978), Borjas (1985), and Friedberg (2000). For Italy, see Brandolini et al. (2005) and Accetturo and Infante (2010).

${ }^{2}$ The result is opposite to that found by Niesing et al. (1994). By analysing the high unemployment rates of ethnic minorities in the Netherlands, they conclude many 
Table 11 Robustness check: irregular aliens

\begin{tabular}{cccc} 
& $\begin{array}{c}{[\mathbf{1}]} \\
\text { Activity } \\
\text { rate }\end{array}$ & $\begin{array}{c}{[\mathbf{2}]} \\
\text { Employment } \\
\text { rate }\end{array}$ & $\begin{array}{c}\text { [3] } \\
\text { Reservation wages (1) }\end{array}$ \\
\hline $\begin{array}{c}\text { Central and Eastern European } \\
\text { Countries }\end{array}$ & 91.6 & 61.4 & $\begin{array}{c}\text { Percentage difference with respect to the } \\
\text { CEEC group: }\end{array}$ \\
Central or Southern America & 94.8 & 74.6 & $0.087^{* * *}$ \\
Near East and North Africa & 86.9 & 56.4 & $(0.031)$ \\
Sub-Saharan Africa & & & $-0.251^{* * *}$ \\
& 92.0 & 59.6 & $(0.045)$ \\
East Asia & & & $-0.078^{* *}$ \\
& 85.5 & 72.6 & $(0.037)$ \\
Central Asia & & & 0.028 \\
No. Obs. & 88.8 & 57.7 & $(0.052)$ \\
\hline
\end{tabular}

Source: Authors' calculations on ISMU dataset.

(1) Percentage differences in computed reservation wages. Stars show significance levels, *** up to 1 per cent, ** between 1 per cent and 5 per cent, ${ }^{*}$ between 5 per cent and 10 per cent. Mean differences are weighted according to the sample design.

Table 12 Robustness check: multireligious countries

\begin{tabular}{|c|c|c|c|}
\hline & $\begin{array}{l}\text { [1] } \\
\text { Activity } \\
\text { rate }\end{array}$ & $\begin{array}{l}\text { [2] } \\
\begin{array}{l}\text { Employment } \\
\text { rate }\end{array}\end{array}$ & $\begin{array}{l}\text { [3] } \\
\text { Reservation wages (1) }\end{array}$ \\
\hline & & & $\begin{array}{l}\text { Percentage difference with respect to the } \\
\text { CEEC group: }\end{array}$ \\
\hline $\begin{array}{c}\text { Central and Eastern European } \\
\text { Countries }\end{array}$ & 79.8 & 69.9 & \\
\hline \multirow[t]{2}{*}{ Central or Southern America } & 84.0 & 71.0 & 0.0296 \\
\hline & & & $(0.0301)$ \\
\hline \multirow[t]{2}{*}{ Near East and North Africa } & 31.0 & 27.7 & $-0.482^{* * *}$ \\
\hline & & & $(0.0470)$ \\
\hline \multirow[t]{2}{*}{ Sub-Saharan Africa } & 76.6 & 66.8 & $0.0893^{* * *}$ \\
\hline & & & $(0.0286)$ \\
\hline \multirow[t]{2}{*}{ East Asia } & 76.9 & 71.2 & -0.0319 \\
\hline & & & $(0.0303)$ \\
\hline \multirow[t]{2}{*}{ Central Asia } & 35.1 & 27.5 & $-0.495^{* * *}$ \\
\hline & & & $(0.0401)$ \\
\hline No. Obs. & & & 8,305 \\
\hline
\end{tabular}

Source: Authors' calculations on ISMU dataset.

(1) Percentage differences in computed reservation wages. Stars show significance levels, *** up to 1 per cent, ** between 1 per cent and 5 per cent, * between 5 per cent and 10 per cent. Mean differences are weighted according to the sample design. 
national groups suffer from a "discrimination in employment possibilities" due to employer choices.

${ }^{3}$ See Accetturo and Infante (2010) for a detailed description of the aggregation centres.

${ }^{4}$ As usual in this literature, we assigned zero years of schooling when the individual does not have any formal education, 8 years for a compulsory school leaving certificate, 13 years for high school and 17 for at least a university degree.

${ }^{5}$ To be clear, we split the immigrants in three groups as regards employment status. The first comprises the inactive population, i.e. those who stated they were housewives or students. The second group is made up of the self-reported unemployed. The third is composed of all employed persons. The "active" group includes both unemployed and employed individuals.

${ }^{6}$ A similar finding is reported by Amuedo-Dorantes and de la Rica (2006) for Spain, according to which African women suffer the lowest occupational attainment, with respect to other immigration groups (in particular if taken into account the years since migration), while Central and South Americans, along with immigrants within EU15, show high level of assimilation.

${ }^{7}$ LFS data are representative for immigration from 2006 on.

${ }^{8}$ In a static framework, with quasi-convex utility functions, the reservation wage is equal to the marginal rate of substitution between leisure and consumption.

${ }^{9}$ For example, the Italian labor Force Survey asks unemployed workers "What is the lowest net monthly wage you would be willing to accept?"

${ }^{10}$ An important advance on this topic is the estimation of structural search models by using the panel structure of many LFSs. This method cannot be used in this paper because the ISMU dataset is compiled on the basis of pooled cross-sections.

${ }^{11}$ Mohanty (2005), in turn, generalises the procedure to cases with multiple selection bias following the approach in Meng and Schmidt (1985). Recently Baffoe-Bonnie (2009) uses a similar framework to study wage differentials.

${ }^{12}$ Spatial dummies include one dummy for each of local labor markets in the partitions of Lombardy.

${ }^{13}$ As one referee pointed out, Years in Italy would also enhance the probability of being willing to work. In a robustness check (available upon request) we inserted this variable in $\mathrm{x}_{1}$ with results much in line with the baseline specification.

${ }^{14}$ Expected wages are also computed for unemployed and inactive individuals. Predicted values are computed without the country of origin dummies coefficients. In this way, we net out the effects of wage level differentials on the computed reservation wages. However, results do not change when we insert country of origin dummies in the predicted values calculations.

${ }^{15} \mathrm{HI}$ for country c is calculated as follows: $H I_{c}=\sum_{r \in R}\left(\frac{P_{r c}}{P_{c}}\right)^{2}$ where $\mathrm{R}$ is the set of religions, $P_{r c}$ is the number of immigrants of religion $\mathrm{r}$ coming from country c and $P_{c}$ is the number of people coming from country c. When in country c there is only one religion, $\mathrm{HI}$ is equal to one.

${ }^{16}$ As a referee points out, another challenge to the identification is the possible discrimination according to religion by employers. A simple way to show that this is not 
likely the case is to run eq. (2) for active women by adding also religion dummies and their interaction with the marital status (linear probability model). The adj. R-squared passes from 0.081 to 0.084 , with an increase by 3.7 per cent. The same regression without country dummies generates a drop of the adj. R-squared to 0.06 (from 0.084). As a comparison, we evaluate the importance of religion dummies in eq. (1). Dropping those variables generates a fall in the adj. R-squared from 0.265 to 0.159 (almost 40 per cent). This implies that while religion dummies (and their interactions) little add to the total explained variance of the hiring decisions by firms ( 4 per cent), they fundamentally contribute to the total variance of the labor supply decision (40 per cent). We also made an additional check. The presence of federal and multi-religious countries (like India) may also possibly create a confounding factor. If religious minorities concentrates in a few states, they are likely to influence the schooling system. This implies that we may have the case in which individuals coming from the same country have a different human capital due to heterogeneous educational system. This heterogeneity may be observed by the employer but not by the econometrician, thus creating a confounding factor in the estimates. In order to cope with this problem, we exclude from the baseline sample (made by multi-religious countries) all the federal states, with results much in line with the baseline. All these results are available upon request.

${ }^{17}$ Another option would have been to merge ISMU data with the LFS. We have decided not to go in this direction because of the great differences between the two surveys in terms of data collection and reference population.

${ }^{18}$ This is due to the fact that the dependent variables in the biprobit are highly correlated since they only differ in the values they assume for unemployed individuals. This may generate a collinearity problem between $\lambda_{1}$ and $\lambda_{2}$ in the estimate of the wage equation. A possible way to circumvent this problem is to treat equations (1) and (2) in a sequential way by estimating an Heckprob model. The results, not shown here to save space but available upon request, are in line with those presented in the text.

${ }^{19}$ We define "city" the local labor market of the three most important towns of Lombardy: Milan, Brescia and Bergamo.

${ }^{20}$ Reported figures are quite similar to those in Table 2 since the regular aliens constitute almost 90 per cent of the ISMU sample.

${ }^{21}$ This result is confirmed by Constant and Zimmermann (2005).

${ }^{22}$ The extension to other regions provides very similar results since immigrants in Italy mostly settle in the North.

\section{Appendix}

Appendix 1. National groups and countries of origin

(Herfindhal index of religions in parenthesis)

Central and Eastern European Countries: Bulgaria (0.42), Czech Rep. (0.46), Estonia (0.33), Latvia (0.38), Lithuania (0.36), Poland (0.66), Romania (0.43), Slovakia (0.62), Slovenia (0.34), Hungary (0.56), Albania (0.30), Belarus (0.70), Bosnia-Herzegovina (0.34), Croatia (0.33), Serbia-Montenegro (0.34), Macedonia (0.31), Moldova (0.68), Russia (0.46), Turkey (0.68), Ukraine (0.59).

Central and Southern America: Argentina (0.54), Bahamas (0.55), Barbados (1), Belize (1), Bolivia (0.88), Brazil (0.67), Chile (1), Colombia (0.77), Costa Rica (0.55), Cuba (0.40), Dominica (0.78), Dominican Rep. (0.72), Ecuador (0.77), El Salvador (0.58), 
Jamaica (0.37), Guatemala (1), Haiti (1), Honduras (0.72), Mexico (0.94), Nicaragua (1), Panama (0.50), Paraguay (0.83), Peru (0.70), Santa Lucia (1), Trinidad and Tobago (1), Uruguay (0.73), Venezuela (0.58).

Near East and North Africa: Algeria (0.92), Egypt (0.72), Libya (0.76), Morocco (0.81), Tunisia (0.98), Saudi Arabia (1), UAE (1), Jordan (0.53), Bahrain (1), Iran (0.76), Iraq (0.50), Kuwait (1), Lebanon (0.61), Palestine (0.34), Syria (0.66), Yemen (0.25).

Sub-Saharan Africa: Angola (0.41), Benin (0.30), Botswana (1), Burkina Faso (0.44), Burundi (0.45), Cameroon (0.46), Capo Verde (0.73), Central African Rep. (1), Chad, Comores, Congo (0.37), Congo (Dem. Rep.) (0.57), Côte d'Ivoire (0.47), Eritrea (0.31), Ethiopia (0.36), Gabon (0.33), Gambia (0.58), Ghana (0.38), Djibouti (1), Guinea (0.51), Guinea Bissau (0.52), Equatorial Guinea (0.26), Kenya (0.26), Lesotho (0.26), Liberia (0.25), Madagascar (0.52), Malawi (1), Mali (0.88), Mauritania (0.32), Mauritius (0.29), Mozambique (0.59), Namibia (1), Niger (0.36), Nigeria (0.38), Rwanda (0.43), Sao Tome e Principe (1), Seychelles (0.28), Senegal (0.60), Sierra Leone (0.44), Somalia (0.43), South Africa (1), Sudan (1), Tanzania (0.55), Togo (0.38), Uganda (0.72), Zambia (0.59), Zimbabwe (0.50).

East Asia: Cambodia (0.30), China (0.30), North Korea (0.26), South Korea (0.37), Philippines (0.69), Indonesia (0.27), Laos (0.33), Malaysia (0.62), Myanmar (0.50), Singapore (1), Sri Lanka (0.31), Taiwan (1), Thailand (0.53), Vietnam (1).

Central Asia: Afghanistan (0.5), Armenia (1), Azerbaijan (0.55), Bangladesh (0.68), Georgia (1), India (0.25), Kazakhstan (0.36), Kyrgyzstan (1), Nepal (1), Pakistan (0.74), Uzbekistan (0.55).

\section{Appendix 2. A comparison with the self-reported reservation wages in the Italian labor Force Survey}

In this Appendix, we compare our estimates for reservation wages on ISMU data with those provided in the labor Force Survey (LFS). We use on the 2006-08 waves of LFS, as previous ones do not provide information on the citizenship of foreign workers. Moreover, in order to provide a comparable result we concentrate on unemployed females in the 15-64 age bracket residing in the North of the country, ${ }^{22}$ where Lombardy is located. We provide here the answer to the question "What is the lowest net monthly wage you would be willing to accept?" Results (Table 5) show that the magnitude for reservation wages is quite similar across national groups. Moreover, cross-national differences in LFS basically mirror those in our estimates.

Competing interests

The IZA Journal of Migration is committed to the IZA Guiding Principles of Research Integrity. The authors declare that they have observed these principles.

\section{Acknowledgement}

We wish to thank Prof. G. Blangiardo, ISMU, for kindly providing us with the dataset. We are also indebted to the editor of this journal, Corrado Giulietti, and three anonymous referees. We also thank Federico Cingano, Sauro Mocetti, Laura Pagani, Alfonso Rosolia, Alberto Zazzaro, the seminar participants at the Bank of Italy, University of Bari, Bocconi University and AIEL (Sassari, 2009), and Jennifer Parkinson for editorial assistance. The views expressed are the authors' own and do not necessarily reflect those of the Bank of Italy. Usual disclaimers apply

Responsible editor: Corrado Giulietti

\section{Author details}

${ }^{1}$ Structural Economic Analysis Department - Bank of Italy, Rome, Italy. ${ }^{2}$ Economic and Financial Statistics Department Bank of Italy, Rome, Italy. 


\section{References}

Accetturo A, Infante L (2010) Immigrant earnings in the Italian labor market. Giornale degli Economisti e Annali d'Economia 69(1):1-27

Addison JT, Centeno M, Portugal P (2004) "Reservation wages, search duration and accepted wages in Europe". IZA Discussion Paper(1252)

Addison JT, Centeno M, Portugal P (2010) Unemployment benefits and reservation wages: key elasticities from a stripped-down job search approach. Economica 77:46-59

Adsera A, Chiswick B (2007) Are there gender and country of origin differences in immigrant labor market outcomes across European destinations? J Popul Econ 20:495-526

Amuedo-Dorantes C, de la Rica S (2006) Labor market assimilation of recent immigrants in Spain. IZA Discussion Paper (2014)

Baffoe-Bonnie J (2009) Black-White wage differentials in a multiple sample selection bias model. Atlantic Econ J 37:1-16

Bevelander P, Groeneveld S (2007) How many hours do you have to work to be integrated? Full time and part time employment of native and ethnic minority women in the Netherlands. IZA Discussion Paper(2684)

Bisin A, Patacchini E, Verdier T, Zenou Y (2008) Are Muslim immigrants different in terms of cultural integration? J Eur Econ Assoc 6(2-3):445-456

Blangiardo G (1993) "Una nuova metodologia del campionamento per le indagini sulla presenza straniera". In: Di Comite L, De Candia M (ed) I fenomeni migratori nel bacino del Mediterraneo. Cacucci Editore, Bari

Blundell R, MaCurdy T (1999) "Labor supply: a review of alternative approaches". In: Ashenfelter O, Card D (ed) Handbook of Labor Economics. Elsevier, North-Holland

Borjas G (1985) "Assimilation, changes in cohort quality and earning of immigrants". J Labor Econ 3:463-489

Brandolini A, Cipollone P, Rosolia A (2005) "Le condizioni di lavoro degli immigrati in Italia". In: Livi Bacci M (ed) L'incidenza economica dell'immigrazione. Giappichelli, Torino

Burdett K, Vishwanath T (1988) Declining reservation wages and learning. Rev Econ Stud 55:655-666

Chiswick B (1978) The effects of Americanization on the earnings of foreign born men. J Polit Econ 86(5):897-921

Clark K, Lindley J (2006) Immigrant labor market assimilation and arrival effects: evidence from UK labor force survey. IZA Discussion Paper(2228)

Constant A, Gataullina L, Zimmermann K (2006) Gender, ethnicity and work. IZA Discussion Paper(2420)

Constant A, Massey DS (2003) "Self-selection, earnings, and out-migration: a longitudinal study of immigrants to Germany". J Popul Econ 16:631-653

Constant A, Zimmermann K (2005) Immigrant performance and selective immigration policy: a European perspective. IZA Discussion Paper(1715)

Duncan K (1992) The value of time in household work: estimates from the NLS data. The Proc Am Council Consum Interests 38:163-170

Dustmann C, Fabbri F (2005) Gender and ethnicity - married immigrants in Britain. Oxford Rev Econ Pol 21:462-484

Dustmann C, Schmidt C (2000) The wage performance of immigrant women: full-time jobs, part-time jobs, and the role of selection. IZA Discussion Paper(233)

Fishe RPH (1982) Unemployment insurance and the reservation wage of the unemployed. Rev Econ Stat 64(1):12-17

Ferber M, Green C (1985) Homemakers' imputed wages: results of the Heckman technique compared with women's own estimates. J Hum Resour 20:90-99

Fernandèz R, Fogli A (2009) Culture: an empirical investigation of beliefs, work and fertility. Am Econ J: Macroecon 1 (1):146-177

Friedberg RM (2000) You can't take it with you? Immigrant Assimilation and the portability of human capital. J Labor Econ 18(2):221-251

Heckman J (1974) "Shadow prices, market wages and labor supply". Econometrica 42:679-694

Heineck G (2004) Does religion influence the labor supply of married women in Germany? J Socio-Econ 33:307-328

Hofler R, Murphy K (1994) Estimating the reservation wages of employed workers using a stochastic frontier. Southern Econ J 60:961-976

Kiefer N, Neumann G (1979) An empirical job-search model with a test of the constant reservation wage hypothesis. J Polit Econ 87:89-107

Kiefer N, Neumann G (1981) Individual Effects in a Nonlinear Model: Explicit Treatment of Heterogeneity in the Empirical Job-Search Model. Econometrica 49:965-979

Meng C, Schmidt P (1985) On the cost of partial observability in bivariate probit model. Int Econ Rev 26:71-85

Mohanty M (2005) An alternative method of estimating the worker's reservation wage. Int Econ J 19(4):501-522

Niesing W, van Praag BMS, Veenman J (1994) The unemployment of ethnic minority groups in Netherlands. J Econometrics 61:173-196

Patel K, Vella F (2007) Immigrant networks and their implications for occupational choices and wages. IZA Discussion Paper(3217)

Sestito P, Viviano E (2011) Reservation wages: explaining some puzzling regional patterns. Labor 25(1):63-88

Sharpe D, Abdel-Ghany M (1997) Measurement of the value of Homemaker's time: an empirical test of the alternative methods of the opportunity cost approach. J Econ Soc Meas 23:149-162

Tunali I (1986) A general structure for models of double selection and an application to a joint migration/earning process with remigration. Res Labor Econ 8:235-282

Vella F (1994) Gender roles and human capital investment: the relationship between traditional attitudes and female labor market performance. Economica 61:191-211

Zaiceva A, Zimmermann K (2007) Children, kitchen, Church: does ethnicity matter? IZA Discussion Paper(3070)

doi:10.1186/2193-9039-2-2

Cite this article as: Accetturo and Infante: Skills or culture? An analysis of the decision to work by immigrant women in Italy. IZA Journal of Migration 2013 2:2. 